\title{
Business process reengineering for the increase in the environmental friendliness of construction
}

\author{
Natalia Shchepkina $^{1 *}$ and Maiya Kramchaninova ${ }^{2}$ \\ ${ }^{1}$ Moscow State University of Civil Engineering, 129337, 26, Yaroslavskoye Shosse, Moscow, Russia \\ ${ }^{2}$ Ukrainian National University, 91043, Molodizhny Block of Buildings, 20a, Luhansk, Ukraine
}

\begin{abstract}
Some current trends and prospects of the world construction industry development from environmental economics position are presented in article. The increased role of innovations and their influence on the competitiveness of construction company in the context of economic, social and ecological components is analyzed. Reduction of some negative impact of all the types of technological processes of construction on the environment is connected with the growth of innovative opportunities. This research proves the need of overcoming technical and technological lag for the development of the construction industry by the means of introduction of business processes management instruments. Justification of reengineering as an effective way of transformation of the technology of construction production is made. The algorithm of stage-by-stage reengineering of business processes, offered in the article is the instrument of effective introduction of technological innovations in the construction companies according to current ecological requirements.
\end{abstract}

\section{Introduction}

Transformational processes in the economy and the industry are always accompanied by the emergence of the new infrastructure, which is necessary for the process of reproduction of the industrial capital. The accelerating urbanization forces the society to consider and analyze the communications between production and the environment [1,2], demanding some measures directed to reduction of technogenic influence, which amplifies according to the increase of scales of construction and intensification of technological processes. In 2017 there was an obvious break of technological innovations in the construction industry. The implementation of new technologies and change of business processes inevitably. The use of digital design tools of BIM, drones, 3D-printing, modular assembly of structures and green design will bring the industry to a new level.

The economic component of technological innovations is directed to the cardinal solution of the production problems, elimination of delays of communication between design office and the building site and improving of the competitiveness.

\footnotetext{
* Corresponding author: angela-1309.m@yandex.ru
} 
Besides, new technical capabilities allow reducing the undesirable consequences for the environment from all the types of construction technological processes. Ecological and social components assume certain benefits from the increase in efficiency of the resources use, such as reduction of construction waste, energy saving, labour protection $[3,4,5]$.

Research proved the importance of business processes management and implementation of the principles of BPM in various organizations $[6,7,8]$. Song, Y.W. and Choi, Y. K. note that in most cases such works were concentrated on the separate processes such as IT support or the general factors, introductions of the BPM system [9, 10, 11]. But rapid development of new technologies continues to demand some development of methodological provisions and recommendations on effective integration of new decisions into work streams. The productivity of the construction industry considerably lags behind other industries, including the lags because of the absence of any developed practice of introduction of technological innovations and the lack of capital investments [12].

According to McCinsey Global Institute, the global increase in the productivity of work in construction is averaged about 1 percent per a year for the last two decades, in comparison with 3-4 percent in other sectors on economy. The lack of investments, lack of any developed practice of introduction of technological innovations, low level of coherence, high risks can be noticed. That explains why the majority of projects of reengineering of business processes (BPR) focused generally on the allied industries.

The integrated approach to business processes management in construction is poorly studied, and has no broad application in the industry. And only a few largest companies considered the possibility of introduction of this system in the business structure [8].

Thus the construction sector needs active advance of new, more effective and ecofriendly technologies. Until recently the expediency of the majority of projects was estimated mainly from the economic point of view, the result of impact on the environment was not included in ecological assessment of the project. But now the degree of ecological validity and reasonableness of the project in many respects determines its chances of future realization.

\section{Methods}

Any technological changes in the operating construction company can lead to the creation of new types of activity. In this case, there is a probability of changes of the business system of the enterprise. The solution of such tasks is possible thanks to the integrated approach to business processes management, from the position of resource opportunities of the company and its readiness for changes [12].

Though the BPR approach was connected with the expectations essential cost saving, up to $60-70 \%$ of projects did not also reach a half of result as not all the important aspects were considered. In this sense, the technique stage-by-stage reengineering in construction can be the main instrument of the smooth transformation, of transition to a new business system, which is capable to adequately answer restrictions of the environment.

The process of reengineering should be broken into the stages, each of which has the accurate purpose: to improve the indicators of time, expenses and quality of the processes.

Such approach will allow expanding significantly the use of effective technologies of management and production at each stage, from planning to completed construction.

The general scheme of reengineering on production is presented in the Figure 1.

Identification of the business processes demanding some alteration according to the chosen strategic objectives is a separate task.

It is possible to interfere with some processes without serious consequences, but at the same time they can form the base for the further redesign of more significant and "difficult" processes. It is expedient to make these processes primary for the intervention 


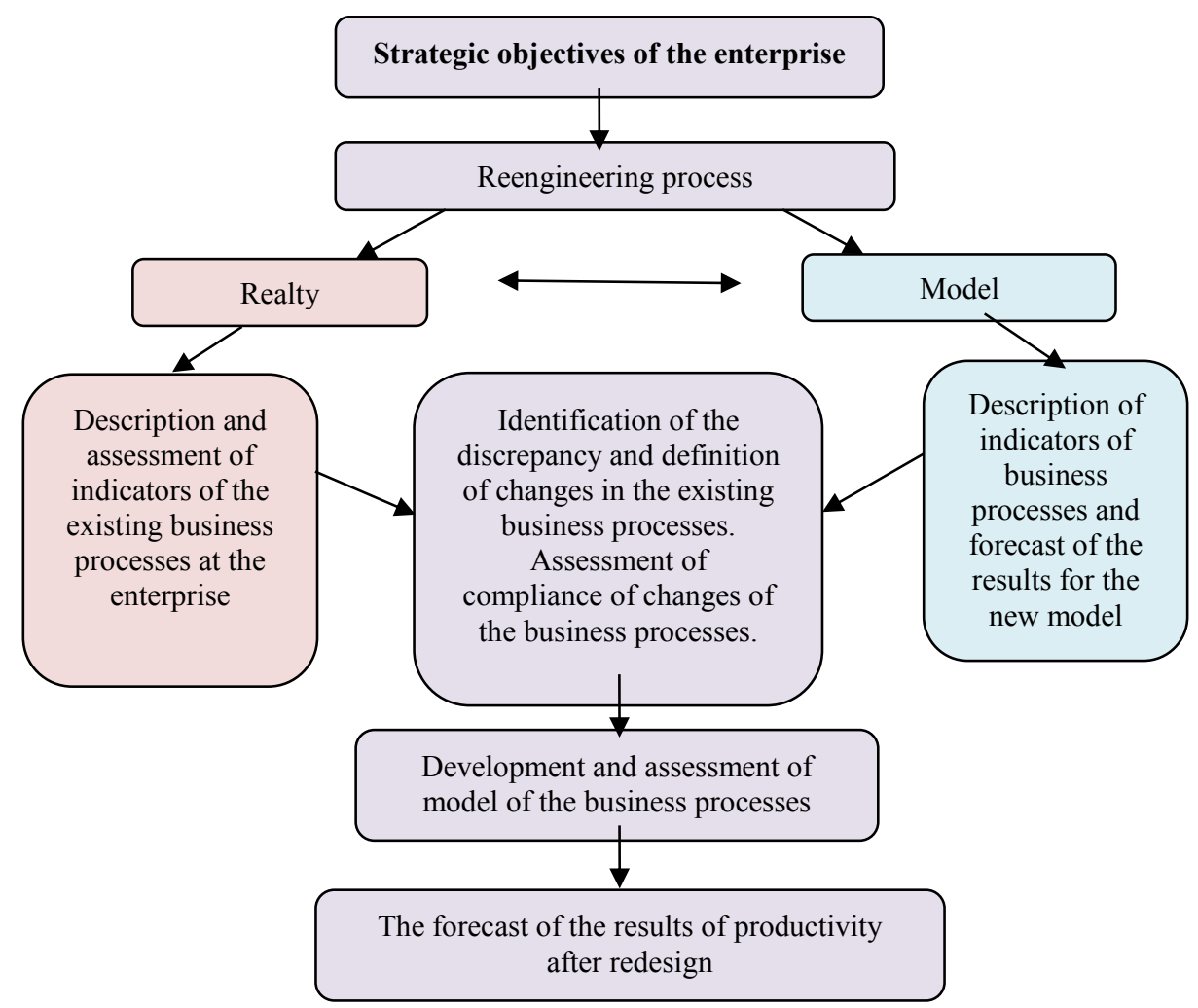

Fig. 1. Recommended stage-by-stage scheme of redesign of the system of business processes according to the objectives.

\section{Results}

As the result of improvement of the offered technique of redesign of the business processes system according to the objectives presented in the Figure 1, some strategic objectives of the enterprise are formulated at the initial stage.

Then, the analysis and check of adequacy of the existing models of business processes to the objectives is made. According to the analysis of the revealed problems and new production requirements the new model of process is developed.

Recommendations are developed and offers on optimization of the existing business processes taking into account time, expenses and quality of processes are formed.

Reengineering is carried out selectively and repeatedly until the majority of processes of the company is not completely redesigned. It will allow minimizing the risks, connected with underestimation of scales of intervention in already existing processes of the construction organization. The result of the algorithm developed within the presented technique of identification of the business processes, which are the priority for reengineering, is the detailed maintenance of the following stages (Figure 2).

Upon the completion of the seventh stage the decision on the transition to the following tasks within the general strategy is made. If changes did not happen or if they were insufficient, it is necessary to return to the previous stages and to begin the design works again, taking into account the revealed mistakes in order to receive some really effective results. 


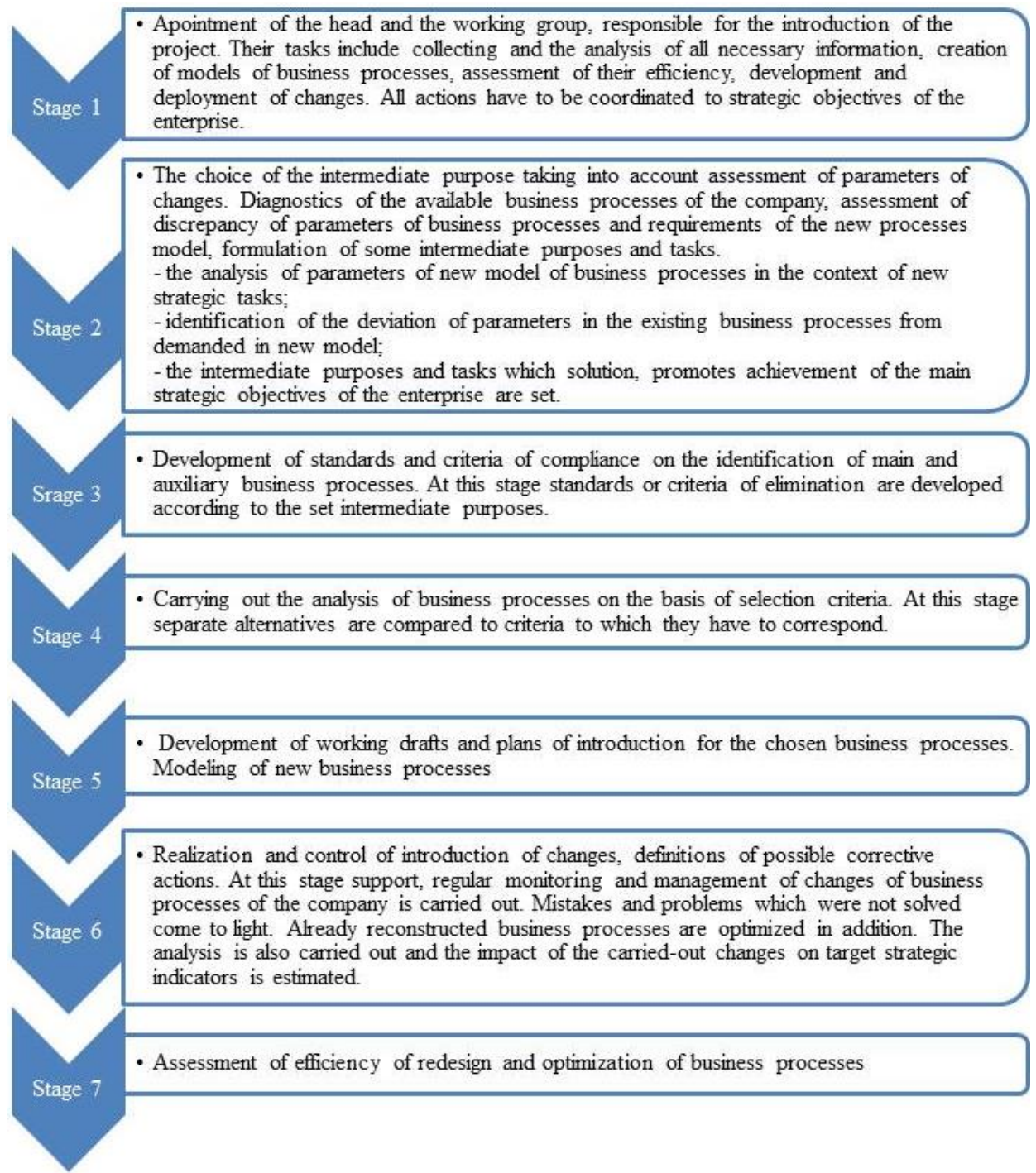

Fig. 2. Stages of identification of the business processes, priority for reengineering.

\section{Discussion}

The complexity of business processes management in construction and the simultaneous need of effective technological development within the environmental economics paradigm causes the implementation of the BPM principles in the construction organizations.

It seems logical to choose the traditional approach, which recommends treating the most important business (in terms of influence on the expected result) as primary. But for any operating company some difficulties of the construction sector in acceptance and adaptation of new technologies often becomes the barrier in the choice of the innovative development strategy. The use of the adequate concept of reengineering as BPM tool will allow the construction organizations to develop the effective mechanism of introduction of technological innovations. These processes have to be carried out systematically and step by step, as well as in parallel in certain cases. It is obvious that significant changes demand 
considerable investments and capital investments. The perspective direction of the research in this context is the possibility of extension of state programmes of support of innovations in the construction industry according to the concept of sustainable development.

\section{Conclusions}

The conducted research allows concluding that there is the increased importance of technical and technological innovations in construction, which is caused by new economic and ecological requirements.

As a result of the research, the need for the development and the use of mechanisms and models of business processes reengineering for construction as the implementation tools of technological innovations is proved.

The stage-by-stage scheme of redesign of the business processes system according to goals as well as the changing paradigm in the construction industry is offered.

Because of the complexity of construction specifics, the algorithm of identification of the business processes priority is developed for the intervention. It essence is in changing selection criteria, depending on requirements of the intermediate purposes, which are formed within the set strategic objective of reengineering.

The change of the principles of the existing technology by the means of this technique is aimed to make the production process more flexible and effective, and at the same time to reduce some undesirable consequences of technogenic influence on the environment.

\section{References}

1. J. Kirchherr, D. Reike, M. Hekkert, Resources, Conservation \& Recycling 127, 221 232 (2017) DOI: doi.org/10.1016/j.resconrec.2017.09.005

2. United Nations, Resolution on Transforming our world: the 2030 Agenda for Sustainable Development (UN, 2015)

3. B. Dave, Construction Innovation 17(1), 50-67 (2017)

4. Y.W. Song, Y.K. Choi, Proceedings of the 28th ISARC 2011 1, 430-435 (2011)

5. M.-Y. Cheng, M.-H. Tsai, Journal of Construction Engineering and Management 129(1), 105-114 (2003)

6. R. Fulford, C. Standing, International Journal of Project Management 32(2), 315-326 (2014)

7. M. Jemala, Technology Implementation and Commercialization. Acta Oeconomica Pragensia 10, 52-69 (2012)

8. S.H. Kwon, K.J. Kim, K. Kim, KSCE Journal Civil Engineering 16, 505 (2012)

9. K. Kunanbayeva, A. Gorovoy, A. Butyrin, MATEC Web of Conferences 193, 05048 (2018)

10. V.S. Lapshin, Management of processes, studies. grant (Mordov University publishing house, Saransk, 2015)

11. W. Xin, Holistica 8(3), 97-102 (2017)

12. S. LaValle, NIT Management Review 52(2), 21-31 (2014) 